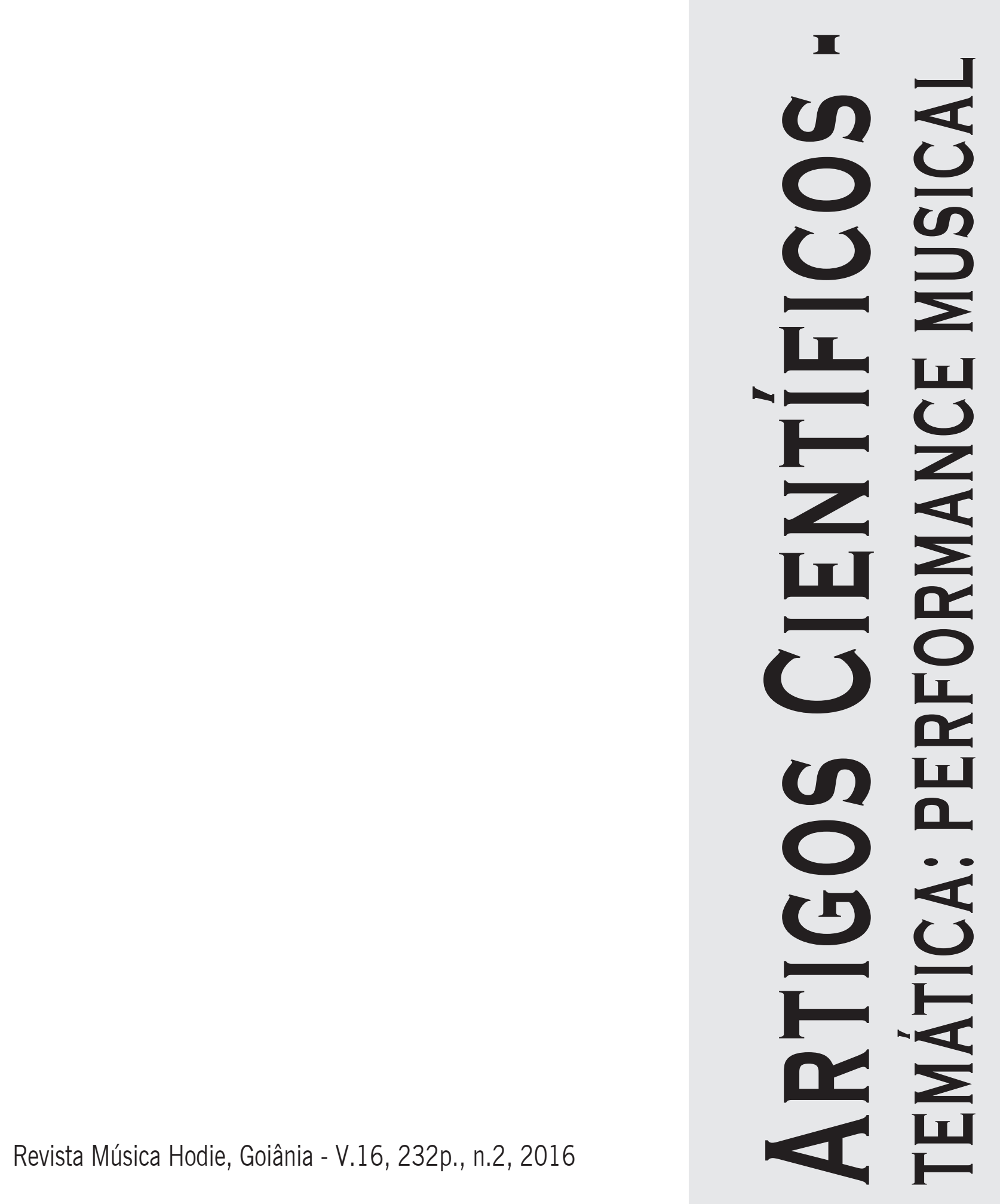




\title{
Análise e aplicações do método Milanov para violino
}

\author{
Paula Farias Bujes (Universidade Federal de Pernambuco, Recife, PE, Brasil)
}

paulabujes@gmail.com

\begin{abstract}
Resumo: O propósito deste artigo é revelar o método para violino do educador búlgaro Trendafil Milanov (19091999). Para isso, apresento os resultados de um estudo qualitativo composto de coleta de dados por meio de técnicas etnográficas diversas. Os temas de pesquisa, confirmados pela análise do método, revelaram seus principais aspectos. O método desenvolve uma ótima noção da geografia do espelho do violino e utiliza a rotação do antebraço como ferramenta essencial para a produção sonora do estágio inicial ao avançado. O uso de canções búlgaras como material musical reciclado é uma das estratégias pedagógicas evidenciadas, acompanhada pelo constante estímulo do senso de autonomia do aluno. Estes resultados revelam um método para violino pouco conhecido e contribuem para a pesquisa no âmbito da pedagogia do violino.

Palavras-chave: Pedagogia da performance; Ensino do instrumento; Pedagogia do violino; Método Milanov; Escola franco-belga; Mudança de posição.
\end{abstract}

Analysis and applications of the Milanov violin method

Abstract: The purpose of this article is to reveal the violin method developed by the Bulgarian educator Trendafil Milanov (1909-1999). To that end, I conducted a qualitative study, which included several ethnographic techniques of data collection. An analysis of the method was completed to complement interview and observation data. Emergent themes related to the method's treatment of violin technique include early exposure to fingerboard geography and the emphasis of forearm rotation as fundamental to bow technique. Additional themes emerged relating to the method's pedagogical strategies, including the use of songs as recycled material and the encouragement of student autonomy. These findings unveil the relatively little known Milanov method and contribute to the growing body of violin pedagogy research.

Keywords: Performance pedagogy; Instrumental teaching; Violin pedagogy; Milanov method; Franco-belgian school; Shifting.

Análisis y aplicaciones del método Milanov para violín

Resumen: El propósito de este artigo es revelar el método para violín desarrollado por el educador búlgaro Trendafil Milanov (1909-1999). Para esto, conduje una investigación cualitativa. La obtención de los datos incluyó diversas técnicas etnográficas y el análisis de ese método fue conducido para complementar los datos de entrevistas y observaciones. Surgieron varios temas relacionados con el abordaje de la técnica violinística que abarca nociones de geografía del espejo y énfasis de la rotación del antebrazo como parte fundamental para la producción sonora, desde el estado inicial al avanzado. Otros temas que surgieron tienen relación con las estrategias pedagógicas del método, como la utilización de canciones búlgaras como material musical recurrente y la estimulación de la autonomía del alumno. Estos resultados revelan un método para violín poco conocido y contribuyen para la investigación en el ámbito de la pedagogía del violín.

Palabras clave: Pedagogía de la performance; Enseñanza del instrumento; Pedagogía del violín; Método Milanov; Escuela franco-belga; Cambio de posición.

\section{Introdução: breve revisão de literatura e razão da pesquisa}

A pedagogia do violino como campo de estudo é marcada por métodos que conquistaram reconhecimento da comunidade de professores de violino por sua comprovada eficácia no tocante à inicialização ao instrumento, seja ela no ambiente de aulas individuais ou no ensino em grupos de violinos ou cordas (ANDERSON e FROST, 1986; APPLEBAUM, 1960; ROLLAND, 1974, 1972; SUZUKI, 1959; ZWEIG, 2008). Ao mesmo tempo, no nível avançado, temos acesso a uma vasta literatura produzida por pedagogos de renome internacional, esta com abordagens múltiplas que vão desde explanações sobre princípios e filosofia de ensino (AUER, 2003; FLESCH, 2000; GALAMIAN, 1962), passando por exercícios práticos de técnica básica ou específica (FISCHER, 1997; RICCI, 2007; ŠEVČIK, 1933) e métodos de escalas (FISCHER, 2012; FLESCH, 1987; GALAMIAN, 1963), até exemplos de co- 
mo estudar certas passagens em apanhados do repertório (FISCHER 2004; FLESCH, 2000). Ademais, é cada vez mais expressiva a quantidade de estudos realizados sobre a eficácia de determinadas metodologias, por vezes comparando-as, no intuito de ampliar nosso entendimento sobre as mesmas (BARBER, 1993; BEHREND, 1998; FISCHBACH, 1972; LIN, 2010; PERKINS, 1995; SCHWANDT, 2006; SMITH, 1995).

No entanto, apesar da grande quantidade de métodos de violino para nível iniciante e intermediário disponível e direcionada para a orientação de professores, estes não parecem dar seguimento concreto ao nível avançado. Dificilmente estabelece-se uma conexão clara entre a metodologia desenvolvida no início do aprendizado e o desenvolvimento sistemático de habilidades de performance que são requerimento para qualquer violinista amador ou profissional, tais como mudança de posição e um entendimento básico dos golpes de arco. Durante meu doutorado tive a alegria de obter acesso ao método Milanov, que introduz de forma simples e clara, mesmo que em forma embrionária, elementos da aprendizagem técnica do instrumento que outros métodos prorrogam sistematicamente. Foi no intuito de aprofundar o entendimento deste diferencial e revelá-lo à comunidade da pedagogia de violino que realizei minha pesquisa de doutorado sobre o método e apresento uma compilação dos resultados da pesquisa neste artigo.

\section{Objetivos e questões de pesquisa}

Os principais objetivos da pesquisa foram obter informações sobre a biografia de Trendafil Milanov, juntamente com sua filosofia e princípios de ensino e analisar e contextualizar seu último método publicado ${ }^{1}$, intitulado "Primeiras Lições de Violino.” (1981) Para tanto, parti das seguintes questões: 1) Qual é a história e a filosofia por trás do método Milanov? 2) Como o método é implementado nas aulas? e 3) Que aspectos do método podem ser recontextualizados na prática docente moderna? Para atender às questões impostas, optei pelo modo de investigação qualitativo.

\section{Metodologia}

Esta pesquisa qualitativa seguiu a metodologia de estudo de caso (CRESWELL, 2007), tendo como sujeito Sophia Ceballos, que na época tinha 8 anos e tomava aulas de violino semanalmente por Yova Milanova, neta de Trendafil Milanov. As aulas tinham duração de uma hora e foram observadas (gerando notas de pesquisa), filmadas e transcritas durante dois semestres completos. O método "Primeiras Lições de Violino" (MILANOV, 1981) foi escrito em dois volumes e nas aulas observou-se a aplicação do segundo volume, que serviu como ponto de partida para estudar a metodologia de Milanov de forma retrogradativa. Como complementação da coleta de dados, realizaram-se entrevistas semiestruturadas (FONTANA e FREY, 1994) com todos os participantes, incluindo Stoika Milanova - filha de Milanov - e Marie Ceballos ${ }^{2}$ - mãe de Sophia, além das participantes citadas anteriormente. No intuito de enriquecer e dar suporte aos resultados, foram utilizadas técnicas etnográficas, como pesquisa narrativa (BRUNER, 1986) - incluindo as histórias da família Milanov - análise de cultura material (HODDER, 1993) - incluindo o próprio método, textos de Milanov (traduzidos ou comentados por Yova Milanova), cartas e fotos - análises por código (aberta e fechada) (EMERSON et al, 1995) e triangulação dos significados dos temas emergentes da coleta de dados (FLICK, 2009). 


\section{Resultados}

Os resultados da pesquisa são os temas emergentes da análise dos dados coletados. Esses temas se referem a aspectos do método, desde as raízes que motivaram sua concepção - fortemente ligadas à biografia de Milanov - passando por uma análise mais detalhada de sua metodologia para o desenvolvimento da técnica do violino, até a evidência de aplicação direta de princípios e filosofia da educação musical propriamente dita aplicada ao ensino do instrumento. A introdução aos temas relativos aos aspectos do violino e da pedagogia é ilustrada por pequenos episódios das aulas observadas. Eis, a seguir, um pequeno panorama destes resultados, os quais abriram um leque de possibilidades para a continuidade da pesquisa sobre o método Milanov.

\subsection{Trendafil Milanov}

Nascido em 1909 na cidade rural de Novo Selo, na Bulgária, Milanov começou a aprender violino com seu pai, violinista amador que também tocava kaval. ${ }^{3}$ Sua mãe e duas irmãs tinham o costume de entoar melodias folclóricas búlgaras enquanto trabalhavam no campo. Milanov seguiu os estudos em violino na Academia de Música de Sofia, onde se graduou em 1934 com orientação do Professor Nikola Abadjiev, este formado no Conservatório de Bruxelas por Henri Marteau. Por volta dos anos 1930, Milanov também realizou uma série de transcrições de melodias folclóricas búlgaras em partitura, trabalho que, aliado a sua experiência como professor de música, estimulou a concepção de seus métodos para violino. Milanov recebeu grande incentivo do governo búlgaro e trabalhou incessantemente em projetos de pesquisa que resultaram em livros de educação musical, métodos para violino, além da formação de grandes talentos provenientes da Bulgária, incluindo Stoika e Yova Milanova, sua filha e neta, respectivamente ${ }^{4}$. Em seu livro "Novos Caminhos para a Educação Musical” (1970), publicado apenas em búlgaro, Milanov credita muito da fundamentação de seu trabalho metodológico à influência de autores de diversos campos, como Dmitri Kabalevsky, Carl Orff, Lev Vygotsky, Aleksei Leontiev, Boris M. Teplov, K. V. Tarasova e D. B. El'konin. Entrevistas com Yova Milanova auxiliaram na tradução e entendimento dos princípios de ensino de Milanov explicados em seu livro, alguns dos quais tem relação com os próximos temas da pesquisa:

1) Música se ensina com música. Deve-se tocar de ouvido desde o estágio inicial;

2) A transposição é a chave para o treinamento do ouvido e para o entendimento da tonalidade;

3) O material musical utilizado deve ser conectado com o ensino de solfejo e teoria;

4) As atividades desenvolvidas e o material musical utilizado devem ser apropriados à idade do aluno;

5) Sistematização do material metodológico de maneira a desenvolver as habilidades musicais e violinísticas harmoniosamente. Esta se dá pela abordagem integrada: prioriza-se a exposição do aluno ao todo antes de prender-se a detalhes.

6) A lei da unidade e conflito dos opostos (materialismo dialético marxista) - o ensino por meio da solução de problemas;

7) Repetição de tarefas com dificuldades progressivas - inspirada na teoria espiral (LENIN, 1915). 


\subsection{Rotação do antebraço}

Sophia toca um trecho do método que trabalha o staccato. Yova observa, e diz: "vejo muito deste movimento [move o braço direito de cima para baixo] e nada deste [gira o antebraço]... tente não gastar tanto arco" Elas repetem o trecho algumas vezes. Yova enfatiza a necessidade de "morder a corda... neste momento o golpe de arco soa muito suave [toca], preciso que ele seja [toca com uma articulação mais forte] assim... Eu inclino a madeira antes de cada nota, com um movimento que vem daqui [mostra a rotação do antebraço] (março de 2011). ${ }^{5}$

Neste tema pude estabelecer uma relação entre a sonoridade madura buscada pelo aluno iniciante/intermediário e o violinista profissional. Uma das motivações da pesquisa foi o encantamento pela beleza e clareza de articulação de som das Milanovas, juntamente com a indagação sobre a relação desta característica com o método Milanov propriamente dito. Com o aprofundamento do estudo constatei que esta clareza do som está diretamente relacionada não somente à maneira com que Milanov sistematizou o desenvolvimento da técnica do arco, mas com a escola franco-belga de arco, ${ }^{6}$ que o influenciou no que se refere ao uso sistemático da rotação do antebraço para a produção sonora. O ensino da técnica de arco é bem fundamentado de acordo com o emprego deste movimento para a produção sonora desde as primeiras lições (através de atividades lúdicas com o arco) até a introdução e aprimoramento de golpes de arco específicos (detaché, martelé, staccato, spiccato, ricochet) no segundo volume do método, que começavam a ser desenvolvidos em algumas aulas observadas. $^{7}$

\section{3 "De cima a baixo" - tocando ao longo do espelho}

Entro na sala de Yova e me surpreendo com Sophia tocando de cima a baixo do espelho do violino, tão naturalmente... Ela não toca perfeitamente o tempo todo, nem muito rápido, o que impressiona é o fato de estar, no nível dela, experimentando as regiões do violino consideradas 'obscuras' nos níveis inicial e intermediário (março de 2011).

Dentre os fatores mais inovadores do método Milanov está o desenvolvimento da navegação precoce ao longo do espelho do violino, ou da habilidade que chamamos mudança de posição. Ainda nas primeiras observações da utilização método em aulas percebi que este seria um tema emergente do estudo, como ilustra o trecho acima. Na época da pesquisa, Sophia trabalhava no segundo volume do método, e o Exemplo 1 abaixo era o exercício em questão:

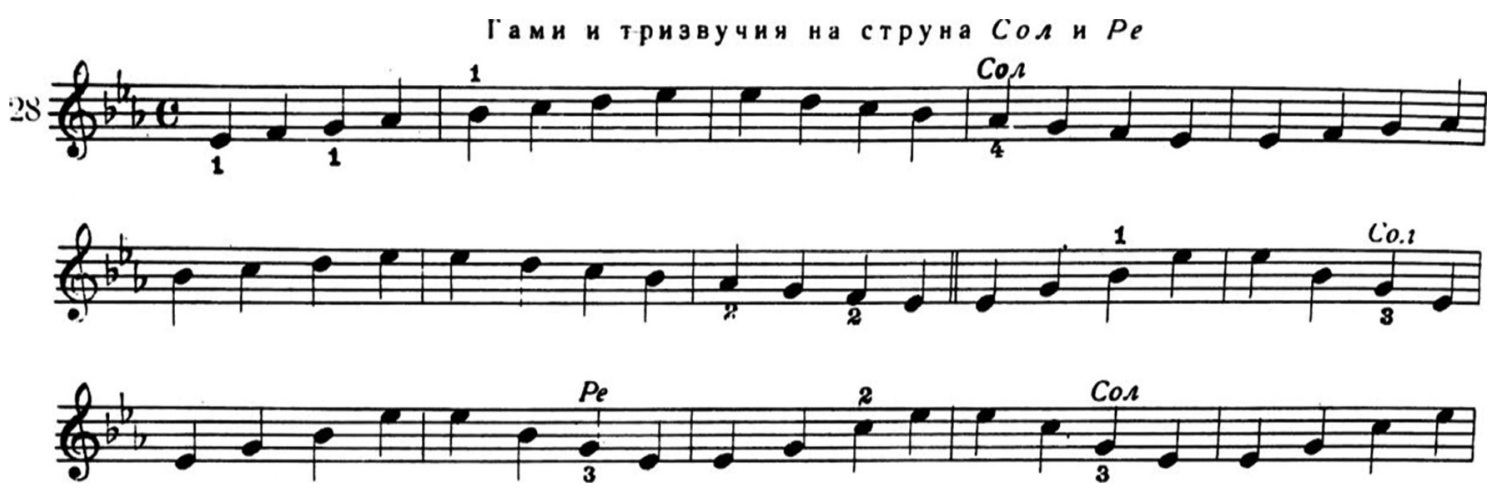

Exemplo 1: Escalas e arpejos conectando as cordas ré e lá. Fonte: MILANOV, 1981, vol. 2, p. 21. 
A simplicidade na estrutura do trecho acima exemplificado permite que alunos experimentem estas regiões do espelho com auxilio dado pelo professor na postura de mão esquerda e colocação do polegar, prática comumente deixada para o nível avançado. Vastos são os estudos para violino que exploram mudanças de posição (RICCI, 2003; ŠEVČIK, 1933) ou o aperfeiçoamento de posições específicas (SITT, 1907) a partir do nível intermediário. Porém, é raro encontrar material que trate sistematicamente de mudanças de posição direcionado aos primeiros estágios de aprendizado do violino. Recorreu-se ao método, portanto, afim de encontrar explicações para esta divergência de abordagem. Nele, Milanov questiona o entendimento do violino em posições (primeira, segunda, etc) e propõe uma visão mais holística do instrumento, sugerindo que, ao invés de aprender as posições, o aluno aprenda o espelho do violino seguindo a direção dos dedos da mão esquerda (MILANOV, 1981). O autor sugere que se desenvolvam desde o estágio inicial não somente os movimentos vertical (pressionando a corda) e lateral (cruzando as cordas), mas também e especialmente o movimento horizontal (ao longo da corda). Utilizando canções simples do folclore búlgaro e canções infantis, Milanov enfatiza a internalização das mesmas e as insere em seu método, explorando a mudança de posição (ou o movimento horizontal, como ele prefere chamar) como habilidade a ser desenvolvida desde o início, valendo-se de atividades lúdicas, como escorregar os dedos ao longo do espelho para iniciar este processo ${ }^{8}$. A transposição destas melodias é a chave para que o aluno entenda em prática, antes da teoria, o conceito de tonalidade.

\subsection{Utilização de canções folclóricas}

Uma das melodias trabalhadas em aula foi Borjano, Borjanke, que é apresentada em diferentes transposições. Yova toca a melodia no piano: "você se lembra dessa canção?" Sophia toca a melodia no violino, não muito segura, e então corrige a relação entre os dedos e recebe um elogio de Yova. Fica feliz, cantarolando a canção (março de 2011).

Através da melodia Borjano, Borjanke, exemplificada abaixo, foram trabalhados diferentes padrões de dedilhados ao longo do método, utilizando o movimento lateral dos dedos da mão esquerda (cruzamento de cordas):

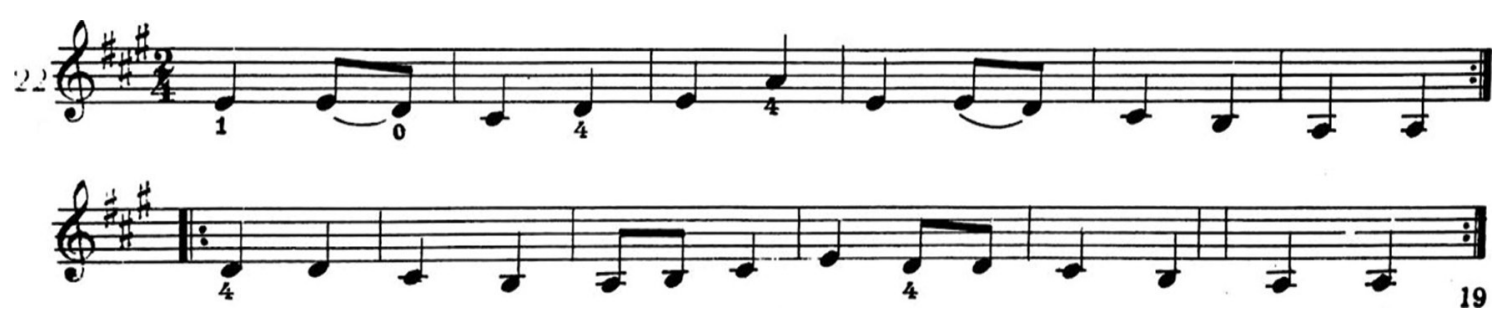

Exemplo 2: Borjano, Borjanke no modo de Lá. Fonte: MILANOV, 1981, vol. 2, p. 19.

Sophia se recorda da melodia que Yova toca ao piano porque ela já havia sido explorada no primeiro volume em diferentes tonalidades, dedilhados e regiões do espelho, então com foco em tocar a melodia de ouvido. Nesta ocasião, a melodia é utilizada para estabelecer relação entre som e símbolo. Nesta mesma aula foi trabalhada a conexão entre as cordas Ré e Lá com a mesma melodia em diversas transposições, disponibilizando-a com lacunas para que o aluno exercite não somente a leitura, mas a escrita musical, como exemplificado abaixo: 


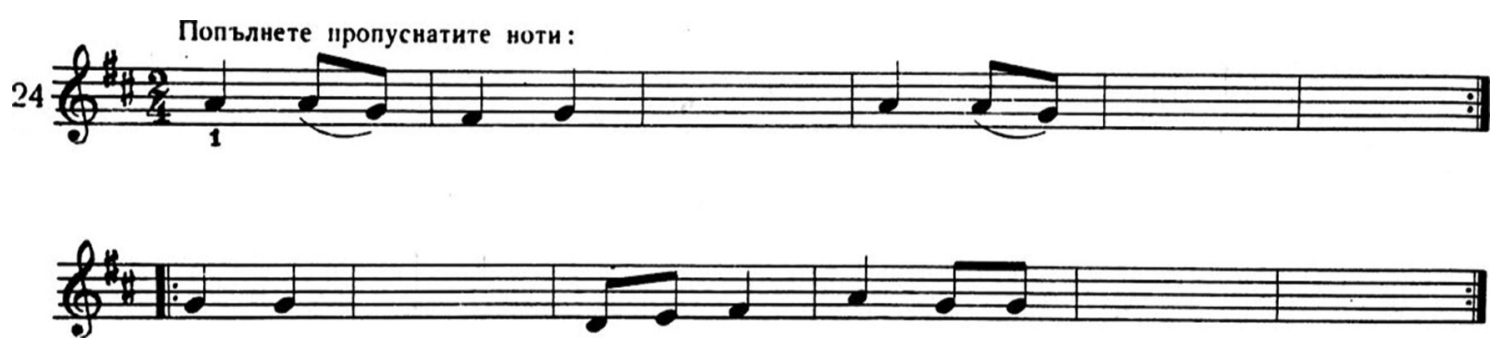

Exemplo 3: Borjano, Borjanke no modo de Ré. Fonte: MILANOV, 1981, vol. 2, p. 20.

No início do segundo volume do método encontramos diversos exercícios com lacunas como o exemplo acima. A prática da transposição de melodias conhecidas desde o início do aprendizado, como observada nesta aula, auxilia Sophia no entendimento da tonalidade e da partitura.

As canções do folclore búlgaro sempre fizeram parte da vida de Milanov, a começar pela sua infância, fase na qual muito as ouviu entoadas por sua mãe e suas irmãs. Na época em que concluiu o curso superior em violino, Milanov já realizava transcrições de melodias folclóricas. Foi, portanto, natural que o pedagogo considerasse a prática do folclore como instrumental para o ensino do violino. Dentre as estratégias pedagógicas do método Milanov está a vasta utilização de melodias do folclore búlgaro como veículo de musicalização e material musical reciclado. Uma canção aprendida por meio do canto e movimentos corporais é reutilizada em múltiplos contextos, para que a constante aquisição de habilidades musicais (ex.: manutenção da pulsação, padrões rítmicos, afinação, transposição, leitura, etc.) e habilidades técnicas ao violino (ex.: produção sonora, divisão e utilização do arco, utilização da mão esquerda, etc.) ocorra sem os obstáculos trazidos pela leitura ou internalização musical. Novas melodias são experienciadas no decorrer do método, composto por 50 canções folclóricas, todas introduzidas durante o primeiro volume. No segundo volume, muitas destas canções reincidem e, gradativamente, introduz-se a leitura musical e as melodias do repertório violinístico, juntamente com a recomendação de estudos, peças e concertos.

\subsection{Autonomia do aluno}

Estaciono em frente à casa de Yova e vejo uma menininha carregando o estojo do violino, a porta da casa lhe é aberta por sua mãe. Sophia tem o cabelo comprido e cacheado, usa franja, óculos cor-de-rosa e aparelho. Eu as cumprimento e entramos na casa de Yova [...] No que a aula começa, Sophia se torna uma orgulhosa violinista, participa ativamente e se orgulha de cada conquista [...] Ao final da aula, Yova questiona Sophia sobre os pontos que precisam de mais atenção e Sophia os enumera sem dificuldades (março de 2011).

Um componente importante no método Milanov é a ênfase no desenvolvimento da autonomia do aluno. Esta ênfase ficou aparente nas observações das aulas, pois havia um senso de responsabilidade em Sophia, que demonstrava seu entendimento sobre o estudo do material e realizava o trabalho consistentemente. Por mais que Yova a encorajasse e a auxiliasse, deixava claro que cada etapa vencida era resultado do empenho de Sophia. Yova afirmou diversas vezes em entrevistas que o papel dela como professora era apenas o de direcionar os estudos de seus alunos: "Eu não alimento meus alunos com cada detalhe da informação, eles têm que aprender a descobrir os caminhos eles mesmos.” Da mesma forma, Yova lembra de Milanov como professor: "ele nunca fez o trabalho por mim, ele me diria: 'está desafinado', mas eu tinha o dever de consertar.” Yova lembra de Milanov não como 
um professor exigente, mas como um mentor que lhe propiciou as grandes oportunidades para superar seu raciocínio. E é neste mesmo sentido que Milanov (1981, p. 4) aponta para a importância de colocar o aluno em situações onde ele próprio identifique e resolva os problemas na execução:

Modern pedagogical psychology claims that real and lasting is only the knowledge that has been achieved through the individual pursuit of the student himself. Therefore, the student has to be put in situations in which [s] he has to solve educational problems. Above all, he has to get accustomed to independently watch, think and work. ${ }^{9}$

Desta forma, esta estratégia pedagógica de Milanov está diretamente relacionada ao campo de pesquisa da auto-regulação. Hoje sabemos que a prática independente é uma importante habilidade para adquirir expertise (ERICSSON, 1993). No ramo da música não é diferente. A pesquisa sobre a prática musical sugere que a prática eficiente é o elemento principal necessário para atingir a proficiência (SLOBODA et al., 1996). Teorias sobre a prática da auto-regulação no estudo constituem um tema que muito tem informado educadores musicais (HALLAM, 2001; MCPHERSON e ZIMMERMAN, 2002; ZIMMERMAN, 2000), especialmente no sentido de reforçar a ideia de que direcionamento, aliado à reflexão e à experiência, são a chave do desenvolvimento das habilidades técnicas e musicais.

\section{Considerações finais}

O presente artigo teve como objetivo apresentar o método Milanov à comunidade acadêmica e docente, ressaltando suas potencialidades para o desenvolvimento de elementos da aprendizagem técnica do instrumento, que são costumeiramente abordadas apenas nos níveis avançados em outros métodos tradicionais de violino. Para tanto, apresentaram-se os resultados de um estudo qualitativo que abrangeu diversas técnicas de coletas de dados e análise dos mesmos, resultando em um panorama de três temáticas principais emergentes do método: a biografia de Milanov, juntamente com seus princípios de ensino, aspectos da sistematização do desenvolvimento da técnica violinística e estratégias pedagógicas. Dentre estas, foi possível refletir sobre peculiaridades dos seus princípios de ensino. Neste sentido, a ideia de que música se ensina com música e de que o aluno iniciante deve tocar de ouvido se relacionam diretamente com a utilização de canções folclóricas. A abordagem integrada - do todo antes dos detalhes, do abstrato e da experiência antes do conceito - também tem relação com o uso de melodias folclóricas, uma vez que, no momento que cantamos a melodia, utilizamos outro veículo musical que não o instrumento para abordar a música na sua integralidade. A abordagem integrada é mais uma vez reforçada ao explorarmos regiões diferentes do violino com a mão esquerda desde cedo. É esta liberdade da mão esquerda que possibilita a utilização da transposição como chave do treinamento do ouvido e do entendimento da tonalidade.

A teoria espiral de Milanov prevê que cada repetição de um conceito aprendido tenha o intuito de expandir outros conhecimentos e habilidades. A utilização repetida das canções também permite que elas funcionem como esse conceito. Da mesma forma, a utilização da rotação do antebraço direito e o movimento horizontal da mão esquerda evoluem desde suas formas elementares por meio de atividades lúdicas até que estes movimentos atinjam sua maturidade com refinamento, servindo para auxiliar na produção sonora e afinação. A estratégia pedagógica que estimula autonomia do aluno é fortemente relacionada à influência da dialética marxista como modelo de problematização. 
É complexa a rede deixada pela trajetória de Trendafil Milanov, que compreende desde sua formação como educador e violinista, seus princípios e filosofia de ensino e estratégias pedagógicas fundamentadas com primor, tudo no intuito de sistematizar o ensino do violino com excelência. Os diferenciais do método Milanov já despertam não somente a curiosidade da comunidade acadêmica no âmbito da educação musical (STRICKLAND, 2013; SOUTH, 2013) e da pedagogia do violino (SALLES, 2014), como estimulam expansão dos nossos estudos de suas bases teóricas em relação ao meio acadêmico brasileiro (MARTINS et al, 2014) e da adaptação do método ao contexto brasileiro (SANTOS et al, 2014) na Universidade Federal de Pernambuco (UFPE). Como fruto destes estudos, cerca de dez lições (capítulos) do método já estão traduzidos para o português e adaptados com canções brasileiras. À medida em que adaptamos o método, os resultados estão sendo implementados em laboratório pedagógico utilizando o viés metodológico da pesquisa-ação (AGUIAR et al, 2015). A pesquisa do método Milanov é portanto continuada e transformada pela experiência dos alunos de graduação da UFPE como participantes da adaptação e contextualização do método para utilização no Brasil.

\section{Notas}

1 Todos os métodos de Milanov foram escritos no idioma búlgaro. O método analisado neste estudo está sendo traduzido para a língua inglesa, ainda não publicado. Além dele, Milanov publicou um método em 5 volumes que se traduz para "Escola de Violino” (1958). Sua filha Stoika Milanova tem manuscritos de seu último método, nunca publicado.

2 No caso de Sophia e Marie Ceballos, pseudônimos foram escolhidos para proteger a identidade dos participantes. No entanto, Yova e Stoika Milanova fazem parte da tradição Milanov e acharam mais natural que fossem identificadas por seus nomes reais.

3 Kaval é um aerofone cilíndrico originário da região dos Balcãs.

4 Stoika Milanova é citada como uma das grandes violinistas do século XX (ROTH, 1997). Foi aluna de David Oistrakh, vencedora da "Competição Internacional Carl Flesch" (1970) e segunda colocada na "Competição Internacional Rainha Elizabeth” (1967). Yova Milanova iniciou sua carreira como violinista ainda na infância e foi vencedora da "Competição Internacional Maria Canals" na Espanha. Atualmente dirige a primeira escola de música a implementar o método Milanov nos Estados Unidos.

${ }^{5}$ Os trechos que introduzem cada tema de pesquisa desta seção e posteriores são uma citações das notas de pesquisa provenientes das observações.

${ }^{6}$ Como mencionado acima, Milanov foi aluno de Nikola Abadjiev, violinista búlgaro formado pelo Conservatório de Bruxelas (Bélgica), que foi aluno de Henri Marteau no Conservatório de Paris (França). Existem diversas referências à excelência da escola franco-belga de violino, principalmente no que se refere à sonoridade e ao uso do arco (ver BUJES, 2013, p. 96 e 97).

7 Para uma análise mais detalhada da metodologia de Milanov e a técnica de arco, ver BUJES, 2003, p. 98-104.

8 Para uma análise detalhada de como Milanov desenvolve a técnica de mudança de posição em seu método, ver BUJES, 2013, p. 85-93).

9 A psicopedagogia moderna afirma que o único conhecimento real e duradouro é aquele que foi aprendido através da busca do próprio aluno. Isto significa que o aluno deve ser colocado em situações nas quais tem de resolver problemas educativos. Acima de tudo, alunos devem acostumar-se a observar, pensar e trabalhar independentemente. (Tradução minha)

\section{Referências}

AGUIAR, D.; BUJES, P. F.; MARTINS, J. L. S; SANTOS, S. V.; BARBOSA; E. N. Pesquisa-ação e método Milanov para violino: um estudo preliminar de aplicação no panorama brasileiro. In: SEMINÁRIO NACIONAL DE PESQUISA EM MÚSICA DA UNIVERSIDADE FEDERAL DE GOIÁS, 15., 2015, Goiânia. Anais do XV SEMPEM, Goiânia, 2015, 288-291. Disponível em: <https://mestrado.emac.ufg.br/up/270/o/150_SEMPEM_interativo_8_out_2015.pdf>. Acesso em: 14 fev 2016. 
ANDERSON, G. E.; FROST, R. S. All for strings. v.1. San Diego: Kjos, 1986.

APPLEBAUM, S. The Belwin string builder. Long Island: Belwin, 1960.

AUER, L. Violin playing as I teach it. New York: Frederick A. Stokes, 1921.

BARBER, B. Traditional and Suzuki Teaching: a comparison. American Suzuki Journal, Boulder, n. 22, p. 18-36, 1993.

BEHREND, L. The Suzuki approach. Miami: Summy-Birchard Music, 1998.

BRUNER, E. M. Ethnography as narrative. In: TURNER, V. W.; BRUNER, E. M. (Ed.) The Anthropology of Experience. Urbana: Board of Trustees of The University of Illinois, 1986, p. 139-158.

BUJES, P. F. "It's easier if you have a system": Analysis and applications of the Milanov violin method. Tese de Doutorado. Louisiana State University, 2013. Baton Rouge: LSU, 2013.

CRESWELL, J. W. Ivestigação qualitativa e projeto de pesquisa: Escolhendo entre cinco abordagens. Porto Alegre: Penso, 2014.

EMERSON, R. M.; FRETZ, R. I.; SHAW, L. I. Writing ethnographic fieldnotes. Chicago: The University of Chicago Press, 1995.

ERICSSON, K. A.; KRAMPE, R. T.; TESCH-ROMER, C. The role of deliberate practice in the acquisition of expert performance. Psychological Review, n. 100, p. 363-406, 1993.

FISCHBACH, G. A. Comprehensive performance project in violin literature and an essay consisting of a comparative study of the teaching methods of Samuel Applebaum and Paul Rolland. University of Iowa. Tese de Doutorado. University Heights: UI, 1972.

FLESCH, C. Scale system: Scale exercises in all major and minor keys for daily study. Ed. Max Rostal. New York: Carl Fischer, 1987.

FLESCH, C. The art of violin playing. Ed. Eric Rosenblith. v.1. New York: Carl Fischer, 2000.

FLICK, U. An introduction to qualitative research. Londres: SAGE Publications Ltda, 2009.

FONTANA, A.; FREY, J. H. The interview. In: DENZIN, N. K.; LINCOLN, Y. S. (Ed.) Handbook of qualitative research, Londres: Sage, 1994, p. 393-402.

GALAMIAN, I. Principles of violin playing and teaching. Englewood Cliffs: Prentice-Hall, 1962.

HODDER, I. The narrative and rhetoric of material culture sequences. World Archaeology, n. 25, p. 268-282, 1993.

LENIN, V. I. Lenin's Collected Works: On the Question of Dialectics. 1915. Disponível em: http:// www.marxists.org/archive/lenin/works/1914/cons-logic/summary.htm>. Acesso em: 14 fev 2016.

MARTINS, J. L. S.; GAMA, M. C.; BUJES, P. F. Levantamento bibliográfico a partir de princípios de ensino propostos por Trendafil Milanov (1909-1999). In: ENCONTRO REGIONAL NORDESTE DA ASSOCIAÇÃO BRASILEIRA DE EDUCAÇÃO MUSICAL, 12., 2014, São Luís. Disponível em: <http://abemeducacaomusical.com.br/conferencias/index.php/regional_nordeste/nordeste/paper/view/646/156>. Acesso em: 14 fev 2016.

MILANOV, T. Violin School. Sofia: Musica, 1958.

MILANOV, T. First Violin Lessons. Sofia: Musica, 1981.

PERKINS, M. M. A Comparison of Violin Techniques: Kato Havas, Paul Rolland, and Shinichi Suzuki. Bloomington: American String Teachers Association, 1995. 
RICCI, R. Ricci on glissando: The shortcut to violin technique. Gregory Zaya (Ed.). Bloomington: Indiana University Press, 2007.

ROLLAND, P. Prelude to string playing. New York: Boosey \& Hawkes, 1972.

ROLLAND, P. and MUTSCHLER, M. The teaching of action in string playing: developmental and remedial techniques. Bloomington: American String Teachers Association, 1974.

ROTH, H. Violin virtuosos: from Paganini to the $21^{\text {st }}$ century. Los Angeles: California Classics Books, 1997.

SALLES, M. I. Proposta de Ensino para Professores Suzuki - com inclusão de Princípios dos Métodos Paul Rolland, Kató Havas e da Pedagogia Waldorf. In: CONGRESSO DA ASSOCIAÇÃO BRASILEIRA DE PERFORMANCE MUSICAL, 2., 2014. Vitória. Anais do II Congresso da ABRAPEM. Vitória, 2014, p. 294-301. Disponível em: <http://periodicos.ufes.br/abrapem/article/ view/7541/5315>. Acesso em: 14 fev 2016.

SANTOS, S. V.; BARBOSA, E. N.; BUJES, P. F. A inserção de canções do folclore brasileiro no método Milanov de violino: análise e substituição de melodias. In: ENCONTRO REGIONAL NORDESTE DA ASSOCIAÇÃO BRASILEIRA DE EDUCAÇÃO MUSICAL, 12., 2014, São Luís. Disponível em: <http://abemeducacaomusical.com.br/conferencias/index.php/regional_nordeste/nordeste/paper/view/650/159>. Acesso em: 14 fev 2016.

SCHWANDT, J. An Integration of select pedagogical techniques of Paul Rolland with graded violin and viola repertoire of Shinichi Suzuki. Tese de Doutorado. University of Oregon. 2006, Eugene: UO, 2006.

SITT, H. Études for the violin. New York: Schirmer, 1907.

SLOBODA, J. A.; DAVIDSON, J. W.; HOWE, M. J. A.; MOORE, D. G. The role of practice in the development of performing musicians. British Journal of Psychology, n. 87, 287-309, 1996.

SMITH, C. M. The effect of finger placement markers on the development of intonation accuracy in beginning string students. Dialogue in Instrumental Music Education, n. 9, 62-70, 1985.

SOUTH, A. L. An examination of middle school band students' ability to match pitch following short-term vocal technique training. Dissertação de Mestrado. Louisiana State University, 2013. Baton Rouge: LSU, 2013.

STRICKLAND, K. E. The effect of real-time pitch tracking and correction on high school instrumentalists' tuning accuracy. Tese de Doutorado. Louisiana State University, 2013. Baton Rouge: LSU, 2013.

SUZUKI, S. Suzuki violin school. New Jersey: Summy-Birchard, 1959.

ŠEVČÍK, O. Shifting the position and preparatory scale-studies for the violin, op. 8. New York: G. Schirmer, 1933.

ZWEIG, M. Mimi Zweig string pedagogy. Bloomington: Mimi Zweig String Pedagogy, 2008. 3 DVDs.

Paula Farias Bujes - Professora de violino na Universidade Federal de Pernambuco e doutora em violino pela Universidade Estadual da Louisiana (EUA). Combina sua atividade docente com a pesquisa sobre o método Milanov para violino e uma intensa agenda de recitais pelo Brasil e exterior. Apresentou trabalhos recentemente no $32^{\circ}$ Congresso Mundial da ISME e no XXVI Congresso da ANPPOM. Atua há mais de dez anos no duo Paula Bujes e Pedro Huff (violino e violoncelo), que no momento se dedica à execução de obras brasileiras para a formação. 